\title{
INTERPROFESSIONAL EDUCATION: AN OVERVIEW OF SIX INITITATIVES ACROSS THE SCHOOLS OF HEALTH AT A SINGLE UNIVERSITY
}

\section{ABSTRACT}

The benefits of interprofessional education (IPE) amongst health professionals are well documented, however, the implementation of interprofessional initiatives across the United States (US) is inconsistent. This report describes the development and content of a number of IPE initiatives that are in the early stages of development and implementation at the University of California, Davis, US. The article describes several important factors that were found to be necessary for the initial implementation of these IPE initiatives. Evaluation data from these initiatives, which is providing a range of positive outcomes, is also presented and discussed in relation to the wider IPE literature.

\section{INTRODUCTION}

Interprofessional education (IPE) has been defined as an approach where members of more than one health or social care profession learn interactively together, for the explicit purpose of improving interprofessional collaboration and/or the health/well being of patients/clients (Reeves, Perrier, Goldman, Freeth \& Zwarenstein 2013). The benefits of IPE amongst health professionals are well documented (e.g. Barr, Koppel, Reeves, Hammick \& Freeth, 2005) and there is evidence of the positive effects of IPE on healthcare outcomes (Reeves et al 2013).

However, while several requirements have been identified as essential for the successful implementation of IPE including support and budgetary resources, creation of an academic calendar, and a requirement for the participation of all healthcare programs (e.g. Aston et al 2012), implementation of IPE remains an activity where local contextual differences result in a poor idea of the width of implementation issues which may affect the successful adoption of this type of education.

This report describes the development and content of such initiatives in the early stages of development at the University of California, Davis (UCD).

\section{BACKGROUND}

UCD is a public teaching and research university and is located on two campuses, one in Sacramento and the other in Davis, California. Professions involved in IPE initiatives at UCD include public health students, pharmacy residents, physician assistant/family nurse practitioners students, health Informatics graduate students, medical students and residents, 
and graduate nursing students. The current IPE initiatives include both formal and informal educational and research programs. Their creation was decided upon through interviews with key faculty and staff, and searches of the literature for best IPE practice. As IPE is a key approach in UCD's strategic plan, all initiatives are fully endorsed and sponsored.

\section{EMERGING INITIAITVES}

Below we describe and discuss six IPE initiatives which are underway at UCD. We also include an outline of any associated evaluation activities.

\section{Core competencies in pain management}

There is no common understanding of what constitutes prelicensure core competencies in pain management across major healthcare professions. This absence of consensus may be an important reason that prelicensure clinical education is lacking comprehensive instruction regarding pain. The goal of the interprofessional pain management competency program is to create core competencies for learners that will ultimately change how healthcare professionals respond to and manage pain. The project, which commenced in Fall 2011 with an examination of existing competencies and the state of pain content in curricula across multiple professions, is jointly led by the schools of medicine and nursing. Following collaboration with 30 interprofessional leaders from the US, Canada, and the United Kingdom, interprofessional consensus-derived competencies were developed that are to be presented to professional organizations for endorsement during Spring 2013. Future project phases will begin later in the year, and include development of curricular modules and learning activities for dissemination with follow-up assessment of impact.

\section{Doctoring}

The doctoring curriculum brings together groups of 8-9 students from the family nurse practitioner program, physician assistant program and $1^{\text {st }}$ year medical students with a qualified practicing clinician facilitator (often paired with a $4^{\text {th }}$ year medical student) to learn the skills of physical assessment in the classroom setting. Students meet for a 2-hour weekly session over a 10-week period. A variety of different teaching methods are used including small group and dyad practice (where students are provided with the opportunity to practice their assessment skills under supervision). Future plans include the expansion of the program to include history taking, medical documentation and clinical reasoning. To date, 139 students have undertaken the program. Preliminary findings from questionnaire data suggest the program improves students' attitude to IPE.

\section{Code team training}


In order to address the limited exposure of residents and nurses to code blue events (i.e. an event which requires patient resuscitation or in which patients are determined to be in need of immediate clinical attention), interprofessional education, in the form of code team training using high fidelity simulation, has been developed for resident physicians, nurses, pharmacists and respiratory therapists. The first 12 months of this project has comprised the development of tools (including simulators, and mobile devices), curriculum design, and implementation of the training programme and the initiation of in-situ code training events on a number of wards within the Health System. So far, 230 students have undertaken code team traininig and feedback suggest that it has had a positive effect on teamwork and communication skills.

\section{Interprofessional geriatric team training elective}

This 2-day course has been designed to test and refine experiential approaches to teaching the collaborative problem solving skills required of interprofessional teams. These approaches will then be used to train home based primary care teams, who care for older veterans with complex chronic diseases, in rural Northern California. Members of these teams will function as clinical preceptors to nursing, social work, human and veterinary medicine students registered on an interprofessional training elective. The course has been submitted for approval within the schools of medicine, social work, nursing and veterinary medicine. By September 2013, primary care teams and academic faculty will have participated in the 2-day course. In February 2014, it is anticipated that 8-12 students will be registered on the training elective.

\section{Improving Quality in Health Care Using an Evidence Base}

This module is shared between students from medicine (including physician's assistants), nursing, informatics, and public health. Through group work, case studies, and seminars, this interprofessional learning experience, enables students to examine the design, implementation, and evaluation of quality and performance improvement. To date, 11 students have completed the module. It is evident from student feedback that participation in this module helps students to appreciate other professional perspectives as opposed to just their own.

\section{Interprofessional book club}

The interprofessional book club runs monthly meetings in which UC Davis health system staff, faculty, and students, read selected books together to help understand the populations served by the UCD health system. For example, topics explored have included race, class and culture. This year's book was The Warmth of Other Suns by Isabel Wilkerson. Reading 
and discussion have provided book club members with an understanding of the perspectives and interactions and social determinants that lead to health disparities within the African American geriatric population, a population who migrated to the Sacramento region and who are now among those served by the UCD health system. Between 20 and 30 participants attend the meetings and preliminarily evidence suggests that they value this opportunity for cross-generational, interprofessional dialogue which broadens their perspective on healthcare.

\section{DISCUSSION}

The IPE initiatives described in this report are in the early stages of development across UCD. These initiatives span undergraduate and postgraduate students, and are diverse with regards to how they have been structured and delivered. The evaluation of these initiatives is beginning to indicate that those who have participated in IPE valued the collaborative dialogue and appreciate the opportunity to develop an understanding of another professional perspective. These data also suggest that IPE can improve student's attitudes to one another. Encouragingly, these emergent findings support other IPE US-based evaluation work (e.g. Edwards et al 2004; Hermann et al 2009).

Traditional uni-professional models of education means that the scheduling of interprofessional classes and courses is highly complex (Barr et al 2005). Often there is almost no space in the curriculum for students to come together for this type of education. Funding constraints may also mean that interprofessional education initiatives may be short lived. Mindful of these constraints, those involved with IPE initiatives at UCD identified several factors as essential for their successful implementation. This has included timely communication across schools and programs, rigorous planning, committed and flexible faculty and budgetary resources for IPE.

Improved professional relationships, enhanced professional competence, improved organisational practice, and improved patient care are some of the benefits of IPE (e.g. Barr et al 2005). At UCD, we believe that where healthcare professionals are trained in carefully planned and well supported IPE initiatives, these benefits will be realised. We hope that this paper provides some insights for academic institutions that are developing similar initiatives.

\section{Declaration of interest}

The authors report no conflicts of interest. The authors alone are responsible for the writing and content of this paper. 


\section{REFERENCES}

Aston SJ, Rheault W, Arenson C, Tappert SK, Stoecker J, Orzoff J, Galitski H, Mackintosh S (2012). Interprofessional education: a review and analysis of programs from three academic health centers; Academic Medicine; 87(7):949-55

Barr H., Koppel I., Reeves S., Hammick M \& Freeth D (2005) Effective Interprofessional Education: Assumption, Argument and Evidence. Blackwell, Oxford.

Edwards, J.C., Van, Sanders, C.W., Fossum, T.V., Sadoski, M., Bramson, R., Wiprud, R.M. 2004: Attitudes of veterinary medical students and medical students toward collaborative learning: an experiment; Journal of Veterinary Medical Education; 31(1):76-8.

Herrmann, J.A., Johnson, Y.J., Troutt, H.F., Prudhomme, T. A. 2009: Publicpolicy practicum to address current issues in human, animal, and ecosystem health; Journal of Veterinary Medical Education 36(4):397-402

Reeves S, Perrier L, Goldman J, Freeth D, Zwarenstein M (2013) Interprofessional education: effects on professional practice and health care outcomes (Update) (Review) The Cochrane collaboration: John WIley and Sons Ltd (issue 3) 